\title{
Erratum
}

\section{Erratum to: Causes and Consequences of Increasing Herbicide Use in Mali}

\author{
Steven Haggblade ${ }^{\mathrm{a}, *}$, Melinda Smale ${ }^{\mathrm{a}}$, Alpha Kergna ${ }^{\mathrm{b}}$, Veronique Theriault ${ }^{\mathrm{a}}$ \\ and Amidou Assima ${ }^{\mathrm{c}}$ \\ ${ }^{a}$ Agricultural, Food and Resource Economics, Michigan State University, East Lansing, MI 48824-1039, \\ USA. \\ E-mails: msmale@msu.edu; theria13@msu.edu \\ ${ }^{\mathrm{b}}$ Institut d'Economie Rurale (IER), BP 258, Rue Mohamed V, Bamako, Mali. \\ E-mail: akergna@yahoo.fr \\ ${ }^{c}$ Projet de Recherche sur Politique Securite Alimentaire au Mali (PRePoSAM), Bamako, Mali. \\ E-mail: amidou.assima@gmail.com \\ *E-mail: blade@msu.edu
}

The European Journal of Development Research (2018) 30, 342. https://doi.org/10.1057/s41287-0170098-z; published online 11 September 2017

Correction to: The European Journal of Development Research (2017), Volume 29, Issue 3. doi: 10.1057/s41287-017-0087-2

The acknowledgment section detailing essential funding information was omitted from the article and should have appeared as follows:

\section{Acknowledgements}

The authors wish to thank Naman Keita and the team of field enumerators he led at the Institut d'Economie Rurale (IER) Programme Economie des Filières for the care and professionalism they exhibited in conducting four rounds of detailed farm household surveys as well as village-level focus groups. We are likewise grateful to Boubacar Diallo, Amadou Diarra, Oyinkan Tasie and Abdramane Traoré for helpful insights into pesticide regulatory structures and markets. Participants at the American Agricultural Economics Association meetings in Boston in August 2016 provided constructive feedback on early analytical results. USAID/Mali has funded this work through the Projet de Recherche sur la politique de sécurité alimentaire au Mali (PRePoSAM) awarded under the Food Security Innovation Lab's Cooperative Agreement Number AID-688-A-16-00001. The authors alone assume responsibility for any remaining errors of fact or interpretation. 